\title{
Methodical Aspects Applied into Teaching Motoric Activities to 10-15 Years Old Schoolchildren
}

\author{
Ardian Shingjergji \\ Elbasan University “ Aleksandër Xhuvani ”, \\ Faculty of Education Sciences, \\ Email: ardianshingjergji@gmail.com
}

\section{Doi:10.5901/jesr.2014.v4n2p271}

\begin{abstract}
Teaching motoric activities during the physical education classes comprises an important methodical aspect of the teacher's work, relying on the didactic principle of adjusting the teaching materials and means as well as the standards of the physical, intellectual and motoric abilities in children of different ages and genders. Being intimately aware of the realities in which the physical education classes take place in some of the 9-year-schools, in Elbasan Town, the object of our study and analyses have been the problems encountered with the methodical activities of the teachers instructing 10 - 15 age-group children, as in the following: The schoolchildren's role and their readiness in acquiring motoric activities The constitution of the motoric wonts and their relations with the structure of motoric activities. The psychological aspect of teaching motoric activities. Methods used in this study include surveying, observation, communication and measurements. Understanding and evidencing these problems will first of all, serve to teachers working with this targeted age-group of children as well as to the preparation of the physical education students at the Faculty of Education Sciences.
\end{abstract}

Keywords: methodical aspect, motoric activity, physical readiness, physical ability, motoric wonts.

\section{Introduction}

Teaching motor actions to schoolchildren is a long and complicated process, requiring the involvement of both teachers and students and aiming to reach specific instructive, educative and health objectives. However, the success for a better acquisition of the curricula or the lack of success thereof, depends on providing certain conditions constituting the teaching process precursory "platform". Among other conditions we can mention the disposition of the teacher and students as well as the availability of the didactic and instructive means.

The teachers' general thought is that students are always inclined to learn. This assertion is true but with some exceptions. The observations, surveys and questionnaires used to understand the teaching -learning process in physical education classes show that the only students amply inclined to learn are the ones who have gained a certain motoric experience, have the proper physical development, be it cultivated or "nature-gifted", as well as demonstrate obvious and affirmed diverting interests to deal with physical exercises and sports. The greatest part of the students does not show to be willing to learn motor actions. In these terms, we can say that it belongs, first of all, to the physical education teachers to promote the students physical, motoric and psychological readiness to acquire new knowledge.

Teaching motor actions requires students to possess a certain level of physical qualities, (suchlike speed, deftness, strength and resistance). In terms of the teaching practices, prior to commencing the classes teaching motoric activities, teachers preliminarily try to understand the development level of the students' physical qualities, (however, studies show that only $40-50 \%$ of teachers try to understand them). In cases the development level of the physical qualities is unsatisfactory, teachers plan more time and make more means available to help them acquire the proper physical preparation. In our schools this has been achieved during the classes' preparatory phase, during regular classes, by providing extracurricular assignments, ( $10 \%$ of the teachers manage to realize this aspect), as well as during other free time sports activities. Regarding the students' motoric readiness, surveys and observations to the teaching processes show that the level of acquisition of the motoric activities curricula depends in a great scale on the level of the students' formation as well as on the scale of their orientation. If they have sufficient and right perceptions of the main elements of the motoric activities, it will not be difficult for them to match motor actions introduced with their previous orientation base, (selected synthesis). The students' motoric perceptions take shape gradually during time their motoric experience increases. At the end of their school age, only children who have developed their experiences, in terms of 
performing motoric activities can exercise combined motor actions and their compound elements. (Dobler, 1961, Lewin, $\mathrm{K}, 1967)$. The rest of the children who cannot do those actions (50-60\% of them), display non-sufficient motoric experience and do not possess certain movements of motoric combination, during their school years. If on the contrary they have been object to the multi-annual and effective teaching of the motor actions they are able and inclined to fulfill the combinations of motoric exercises. (Schreiter, 1963, Blume, 1965). Psychological readiness makes up another aspect of the development methods in education at school. It presupposes the motivation of the students' motor actions, in their learning process. In the physical education, teaching process is successful when reaching objectives persist as dominating motif in the course of the exercising actions. However, the motives, (those with positive tendency), are not usually inherited by students, they are cultivated by since early childhood in their families and later on by their teachers. Teachers realize it by "taking advantage" to their cognitive, amusing, healthy and affirmative interests. The teacher should intend to link the realization of certain objectives not only with the students' narrow interests but even with the group ones. It is only by this way that teaching motives become dominant and motoric exercising renders conscious and active.

At the 9-year schools there are many examples encouraging teaching motives. In the races of sports activities among parallel classes and schools, the success of the group depends on the qualitative level of the acquiring motor actions by each single individual.

In order to ensure a sufficient level of the students' psychological readiness in the teaching process, the teacher selects certain motor actions having stimulative scale of difficulty and at the same time to guarantee their physical and health safety.

\section{Results and Discourse}

\subsection{Role and the impact of the physical readiness in the qualitative acquisition of the motor actions.}

$10 \mathrm{yr}$-old students begin their fifth grade physical education class not only with specialist teacher but even with a series of changes in their bodily motoric system, in their physical physiological and psychological indicators. In Table 1.2, have been presented some of the main(average), physical and psychological indicators for the group-age of the $10-15 \mathrm{yr}$-old students.

The assessment of the students' physical growth has been done on the bases of the harmony among the main anthropometric indicators suchlike: the weight, bodily height, and the chest perimeter. As a rule, the students featuring average anthropometric indicators feature the physiological indicators and the physical and motoric abilities at the same level, too. The opposite occurs with students featuring under-average and lower indicators. The difference among the students with high physiometric indicators, and those with average level indicators varies from $11-32 \%$, whereas the difference among students with average level indicators and the ones with lower level varies from $9-33 \%$.

Their motoric experience, as compared to the first grade pupils (6 years old), is greater but is still continues to be insufficient as compared to the eighth grade students. In the years of the 9-year school cycle they learn more new motor actions in disciplines such as athletics, gymnastics as well as in other sports games. A natural question derives from all this: Do the $10-15$ students have the physical readiness to successfully acquire the physical education curricula?

The observations made by us, (the leading pedagogue and the physical education students, Faculty of Education, "Aleksander Xhuvani" University) with some schools in Elbasan Town, divulge that there are some motor actions that students can be executed only in the conditions of a sufficient level of development in their physical abilities such as the strength, velocity, resistance, elasticity. A feature of the content of the physical education curricula for the V - VIII grade students are exercises with dynamic, kinematic, as well as mix ones, (dynamic-kinematic). The dynamic feature of motor actions is clearly reflected in the dominance of the strength features, (static, locomotor, velocity and the resistant strength) especially in athletics and gymnastics. In sportive games, there are, generally, mixed-structure motor actions, in which the physical abilities and kinematic elements (angles, amplitudes, rhythm, and trajectories) often are alternated with each-other, in the motion qualitative execution priorities, (Kacurri, A. 2000).

What are our data regarding the students' physical readiness? To answer those questions we should refer Table 3 , which reflects the physical readiness average level data for the $10-15$ age group students, according to the curricula disciplines expressed in \%.

As data confirms, the students do not have the necessary physical readiness to acquire various motor actions qualitatively, which brings out the need for a differentiated treatment. More acute results are obtained regarding the physical preparations of V-grade students, since the number of the new motor actions, compared to the VI-VIII grades, is 
more numerous. Also, from our observations and conversations we have ascertained that there are many teachers who think (and act), that the motoric elements predicted by the V- grade curricula should be acquired within the same academic year. This makes them to haste and pay more attention to the technique alone, while forgetting the physical preparation as well as the fact that the motoric elements further imperfection goes on gradually in the successive grades.

\subsection{Formation of the motoric wonts and deftness and their relations with the structure of the motor actions.}

The following have resulted from the observation of the teaching process regarding the formation of the students' motoric wonts and deftness:

First, the quality of perceptions regarding the goals and the ways to achieve them is conditioned by the level of the suitability of the motoric action to be taught.

In fact, the students' motoric envisioning are formed on the bases of the knowledge given by the teacher as well as their own experiences. Our observations show that in $40-50 \%$ of the cases, there exist no clear envisioning in the students' memory about the motoric tasks and the ways to resolve them. Among many cases we are bringing, as an instance, students who have never jumped over the vaulting horse, have never exercised on gym tools, (gym iron bars and parallels). The issue is more acute with the V-grade students, (partly with those of the other grades), who do not have correct envisioning for the greatest part of the motor actions, regarding the aim and the ways they should be executed.

What did we notice and how do our teachers resolve this problem in their daily practice? In order to make motoric tasks as suitable as possible, about $40 \%$ of them plan and realize differentiated motor preparation, by using exercises similar or approximate to the real ones or special exercises. In other cases which do not use this methodic choice, the students do not result to acquire motor actions effectively.

Second, in the first phase of the teaching process, the tests for the motor actions do not result to have the proper result. In most cases, such a result is for the second phase, as well and this is because students do not understand where the success of their efforts depends on, (what are the crucial elements and what ways the second-hand elements are connected to the execution of the motor actions). Especially for the V-Grades, for instance, it results that students cannot execute the backward somersault, because they do not know that rolling speed should increase too much while the bodily weight is transferred on the shoulders' horizontal axis. It has been noticed that, there is inconsistence among the verbal and concrete (visual), cognition, material cognition, (auxiliary exercises) and natural cognition (exercising), which brings a vague orientation base and makes up the cause the students cannot realize motoric tasks. In this aspect, there is no doubt that assistance provided by the teachers takes a crucial importance, in the form of instructions so that students strengthen their orientation base and realize their motoric tasks successfully.

\subsection{The psychological aspects linked with the teaching of the motor actions.}

Some of the most salient psychological elements observed in the teaching of the motor actions to 10-15 yr-old students is the attention, remembering and motoric restraining which comes as a consequence of the protective reflexes. These psychic phenomenona, which emerge in different levels and ages, condition the differentiation in teaching motoric motions. The physical potential is conditioned by the psychical condition. (Antonelli, Salvini, A., 1989). To this regard the following cases are presented:

First case: control of the motoric objects and situations by the students.

The experienced teachers know that the difficulties of accomplishing the motoric tasks depend on the volume of the objects and situations students are faced with. These are psychical operations requiring optimal levels of attention's dispersal and mobility. It results from our observations that $30-40 \%$ of the students are able to consciously control all the motoric elements. What are the ways out teacher act during the teaching process? They divide exercises in logical sequences, teaching them one at a time. Then they make their gradual unification until the motor actions have exercised as a whole. At first sight it looks right but it is noticed that there are many students who cannot perform them correctly. The main cause is that teachers haste to teach the whole set of the elements making their possession very difficult.

Second Case: volume and the speed of information.

The suitability of the motoric task depends too much from the volume of its compound elements. This volume is consequently linked with the students' ability to memorize only the optimal portions of this information. The answer is product of limited situation analyses (Sabiene, F., Rossi, B., Cortili, G., 1986). For the beginners, the information analyses take longer to be perceived and understood, only to be gradually improved while the motoric experiences 
increase.

Our observations show that despite age, gender and the lack of experience, our teachers are oriented solely by using their intuition. So, i.e. the long jump with $2-3$ steps run than with 4-6 steps actually serves to increase the speed of the neuro-muscular sensitivity but not to the attention dispersal into its compound elements. Here the differentiation is almost absent.

Third case: protective reflex and the motoric refraining.

In the physical education curricula there are such motor actions as jumping over the vaulting-horse, exercises in gym tools, etc, bearing even the risks of physical safety. Sensing the risk makes up the main cause generating selfprotective reflexes, the result of which are awkward motions to slowdown and even to complete interruption. The students' learning suitability for exercises is significantly low in cases when risk presence is increasing in them. What results from our observations to the teaching classes is that most of the teachers do not pay the proper attention to this problem. In all cases when they have increased efforts to minimize the unsuccessful motor actions and have increased the safety conditions, the students have accomplished their motoric tasks more correctly.

\section{Conclusions and Recommendations}

1. The successful teaching of the motor actions depends on both the teachers and students' cooperation, aiming to achieve teaching, educating and health objectives of the curricula.

2. Being successful in acquiring the curricula motoric tasks depends on the teachers and students' readiness as well as on the availability of the didactic and teaching means. The methodic and organizing progress of the classes should secure the students' physical, motoric and psychological readiness.

3. The observations accomplished to the physical education classes testify that teaching and acquiring motor actions requires a sufficient level of physical abilities. This is the reason why the teachers should plan, time and again, a period of time to be dedicated solely to the students' preliminary physical preparation, so that they acquire the necessary minimum of their physical readiness. .

4. The students' motoric preparation should suit to the specific features of the motor actions so that they understand the logic of the motions and focus their attention on the main points of their successful execution.

5. Checking the objects of motoric situations and the speed of information depends too much on the level of the students' psychomotor abilities whereas the protective reflexes depend on the scale of getting impressed and the safety during the execution of the motor actions.

6. We believe that identifying, understanding and discussing the problems presented in this study will serve the physical education teachers in 9-year schools in their didactic process as well as to the students of this profile at the Faculty of the Education Sciences in the course of their work in the future.

\section{Bibliography}

Antonelli, Salvini, A., Psicologia dello Sport, (1989), Roma, 5-34.

Gallahue, D.L., Ozmun, J.C. "Understanding Motor Development: Infants children, adolescents, adults".(2006). Indiana State University. Mc. Groë-Hill companies28-41.

Gray, J.K. The Philosophy of Child Development - games and sports Activities (1998). AEDP. Tiranë, 3-28.

Kacurri, A. "Teaching and the qualitative dynamico-kinematic execution of the motor actions, age group 10-14 yrs old". Buletini 1 (2000), Physical Education in School. , ISP, Tiranë, 159-166.

Meinel, K., Schnabel, G., et.al. Teoria del movimento, (1984). Societa Stampa Sportiva, Romë. Autorë të referuar : Blume, (1965), 66. Dobler, (1961) 104. Lewin, K.(1967), 64-65, 69, 73. Schreiter, (1963), 76.

Misja, B., Cina, R., Nika, F., Toçi, B. Bases of the Motion Theory Humane.(2012). Tetovë. Arbëria design, 63-67.

Sabiene, F., Rossi, B., Cortili, G. Fisiologia e Psicologia degli Sport, (1986). Milano, 40-54, 213-300, 236.

Zhurda, Y., Curani, V. Sports Psychology, (1997). Tiranë. Sh.B. "Hipokrati",99-103, 105-116,117-119, 135. 
Table No.1 Indicators of the Physical Growth in 10 - 15 yrs-old Children (average)

\begin{tabular}{|c|c|c|c|c|c|c|}
\hline \multirow{2}{*}{$\begin{array}{c}\text { Age } \\
\text { (yrs) }\end{array}$} & \multicolumn{3}{|c|}{ Boys } & \multicolumn{3}{c|}{ Girls } \\
\cline { 2 - 7 } & Weight & Height & Chest Perimeter & Weight & Height & Chest perimeter \\
\hline 10 & 28,5 & 128,8 & 63,2 & 30,4 & 128,1 & 62,5 \\
\hline 11 & 33,1 & 138,2 & 67,1 & 33,7 & 137,2 & 66,1 \\
\hline 12 & 35,8 & 141,3 & 68,2 & 35,1 & 142,1 & 67,6 \\
\hline 13 & 37,2 & 144,1 & 69,4 & 37,1 & 145,3 & 69,4 \\
\hline 14 & 38,6 & 149,0 & 71,3 & 39,6 & 149,6 & 71,9 \\
\hline 15 & 48,0 & 157,7 & 77,1 & 48,5 & 156,7 & 785 \\
\hline
\end{tabular}

Tabela No.2 Frekuenca e pulsit të nxënësve 10 - 15 vjeçarë (në 1 minutë)

\begin{tabular}{|c|c|c|}
\hline $\begin{array}{c}\text { Age } \\
\text { (yrs) }\end{array}$ & Boys & Girls \\
\hline 10 & 87 & 94 \\
\hline 11 & 84 & 95 \\
\hline 12 & 86 & 92 \\
\hline 13 & 83 & 91 \\
\hline 14 & 85 & 90 \\
\hline 15 & 83 & 89 \\
\hline
\end{tabular}

Table No. 3 The average Level of the Students' Readiness, Grades V - VIII (according to specific disciplines \%)

\begin{tabular}{|c|c|c|c|c|c|c|c|c|}
\hline \multirow{3}{*}{ Curricula Disciplines } & \multicolumn{8}{|c|}{ Grades } \\
\hline & \multicolumn{4}{|c|}{ Boys } & \multicolumn{4}{|c|}{ Girls } \\
\hline & $\mathrm{V}$ & $\mathrm{VI}$ & VII & VIII & V & $\mathrm{VI}$ & VII & VIII \\
\hline \multicolumn{9}{|l|}{ I.Athletics } \\
\hline 1. Running & 70 & 75 & 80 & 90 & 80 & 75 & 50 & 40 \\
\hline Jumping & 20 & 30 & 55 & 60 & 50 & 60 & 40 & 40 \\
\hline 3. Hurling & 10 & 30 & 60 & 70 & 10 & 20 & 40 & 50 \\
\hline \multicolumn{9}{|l|}{ II .Gymnastics } \\
\hline 1. Acrobacy & 50 & 60 & 65 & 70 & 80 & 75 & 60 & 50 \\
\hline Tool Exercises & - & - & 10 & 20 & 30 & 40 & 30 & 35 \\
\hline 3. $\quad$ Jumping & 30 & 40 & 50 & 60 & 15 & 20 & 30 & 30 \\
\hline \multicolumn{9}{|l|}{ III .Sport Games } \\
\hline 1. $\quad$ Basketball & 70 & 75 & 80 & 85 & 50 & 50 & 60 & 70 \\
\hline 2. Volleyball & - & - & 10 & 20 & - & - & 10 & 20 \\
\hline 3. Handball & 50 & 60 & 70 & 80 & 50 & 50 & 60 & 60 \\
\hline
\end{tabular}

